\title{
Study on the prevalence and genetic diversity of Eimeria species from broilers and free-range chickens in KwaZulu-Natal province, South Africa
}

\begin{tabular}{|c|c|}
\hline \multicolumn{2}{|c|}{$\begin{array}{l}\text { Authors: } \\
\text { Abiodun J. Fatoba } \\
\text { Oliver T. Zishiri }{ }^{1} \\
\text { Damer P. Blake }^{2} \\
\text { Sunday O. Peters } \\
\text { Jeffrey Lebepe } \\
\text { Samson Mukaratirwa }^{5} \\
\text { Matthew A. Adeleke }\end{array}$} \\
\hline \multicolumn{2}{|c|}{$\begin{array}{l}\text { Affiliations: } \\
{ }^{1} \text { Discipline of Genetics, } \\
\text { School of Life Sciences, } \\
\text { College of Agriculture, } \\
\text { Engineering and Sciences, } \\
\text { University of KwaZulu-Natal, } \\
\text { Westville, South Africa }\end{array}$} \\
\hline \multicolumn{2}{|c|}{$\begin{array}{l}{ }^{2} \text { Department of Pathobiology } \\
\text { and Population Sciences, } \\
\text { The Royal Veterinary College, } \\
\text { Hawkshead Lane, } \\
\text { Hertfordshire, } \\
\text { United Kingdom }\end{array}$} \\
\hline \multicolumn{2}{|c|}{$\begin{array}{l}{ }^{3} \text { Department of Animal } \\
\text { Science, Berry College, } \\
\text { Mount Berry, Georgia, } \\
\text { United States }\end{array}$} \\
\hline \multicolumn{2}{|c|}{$\begin{array}{l}{ }^{4} \text { Department of Biodiversity } \\
\text { and Evolutionary Biology, } \\
\text { School of Life Sciences, } \\
\text { College of Agriculture, } \\
\text { Engineering and Sciences, } \\
\text { University of KwaZulu-Natal, } \\
\text { Durban, South Africa }\end{array}$} \\
\hline \multicolumn{2}{|c|}{$\begin{array}{l}{ }^{5} \text { Department of Biological } \\
\text { Sciences, School of Life } \\
\text { Sciences, College of } \\
\text { Agriculture, Engineering and } \\
\text { Sciences, University of } \\
\text { KwaZulu-Natal, Durban, } \\
\text { South Africa }\end{array}$} \\
\hline \multicolumn{2}{|c|}{$\begin{array}{l}\text { Corresponding author: } \\
\text { Matthew Adeleke } \\
\text { adelekem@ukzn.ac.za }\end{array}$} \\
\hline \multicolumn{2}{|l|}{ Read online: } \\
\hline 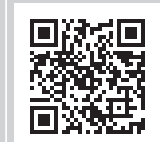 & $\begin{array}{l}\text { Scan this QR } \\
\text { code with your } \\
\text { smart phone or } \\
\text { mobile device } \\
\text { to read online. }\end{array}$ \\
\hline
\end{tabular}

This study was conducted from January to October 2018 with the objective to determine the prevalence and genetic diversity of Eimeria species in broiler and free-range chickens in KwaZulu-Natal province, South Africa. A total of 342 faecal samples were collected from 12 randomly selected healthy broiler chicken farms and 40 free-range chickens from 10 different locations. Faecal samples were screened for the presence of Eimeria oocysts using a standard flotation method. The species of Eimeria isolates were confirmed by amplification of the internal transcribed spacer 1 (ITS-1) partial region and sequences analysis. Among broiler and free-ranging chickens, 19 out of 41 pens (46.3\%) and 25 out of 42 faecal samples (59.5\%) were positive for Eimeria infection. Molecular detection revealed the following species: Eimeria maxima, Eimeria tenella, Eimeria acervulina, Eimeria brunetti and Eimeria mitis in all the samples screened. Similarly, polymerase chain reaction assays specific for three cryptic Eimeria operational taxonomic units were negative for all the samples. Phylogenetic analysis of the ITS-1 sequences supported species identity with the greatest variation detected for E. mitis. This study provides information on the range and identity of Eimeria species, and their genetic relatedness, circulating in commercially reared broilers and free-ranging chickens from different locations in KwaZulu-Natal province.

Keywords: chickens; coccidiosis; Eimeria; genetic diversity; molecular diagnosis; prevalence.

\section{Introduction}

Poultry production has become a major driving force in the economy of many developing countries, which are countries characterised by low income and gross domestic product per capita (Alders \& Pym 2009). South Africa produced 129.3 million chickens throughout the nine provinces in 2017, of which 7\% were from KwaZulu-Natal (South African Poultry Association 2017). The vulnerability of chickens under commercial production to parasitic diseases such as coccidiosis is a major threat to the productivity and viability of the South African poultry industry.

Coccidiosis is an enteric disease that reduces performance and affects the welfare of chickens, leading to high morbidity and mortality in the absence of effective control (Blake \& Tomley 2014). Globally, the annual burden of preventing/controlling coccidiosis has been estimated to exceed $\$ 3$ billion (Blake \& Tomley 2014). Eimeria, a parasite of the phylum Apicomplexa, is the causative agent of this disease, and its species such as Eimeria necatrix, Eimeria maxima, Eimeria acervulina, Eimeria praecox, Eimeria mitis, Eimeria brunetti and Eimeria tenella are also known to infect chickens (Nematollahi, Moghaddam \& Niyazpour 2008). Mixed infections are common (Haug et al. 2008; Jenkins et al. 2008), thereby complicating diagnosis and effective control. The emergence of three cryptic Eimeria genotypes, referred to as operational taxonomic units (OTUs) $\mathrm{x}, \mathrm{y}$ and $\mathrm{z}$, has added further complexity. These were first detected circulating among commercial chickens reared in Australia (Cantacessi et al. 2008). The three OTU genotypes have since been reported in several African countries, such as Nigeria, Tanzania, Ghana, Uganda and Zambia (Clark et al. 2016; Jatau et al. 2016). The widespread occurrence of these cryptic genotypes could pose a significant risk to vaccine development and application (Clark et al. 2016).

Dates : Received: 27 Nov. 2019 | Accepted: 25 June 2020 | Published: 17 Sept. 2020

How to cite this article: Fatoba, A.J., Zishiri, O.T., Blake, D.P., Peters, S.O., Lebepe, J., Mukaratirwa, S., et al. 2020, 'Study on the prevalence and genetic diversity of Eimeria species from broilers and free-range chickens in KwaZulu-Natal province, South Africa', Onderstepoort Journal of Veterinary Research 87(1), a1837. https://doi.org/10.4102/ojvr.v87i1.1837

Copyright: ㄷ 2020. The Authors. Licensee: AOSIS. This work is licensed under the Creative Commons Attribution License. 
Effective control of coccidiosis in chickens relies on strict management practices, supplemented by timely application of anticoccidial drugs and/or vaccines (Godwin \& Morgan 2015) underpinned by proper diagnosis and identification. Traditional diagnostic methods include evaluation of the location and the characteristics of gross pathology (lesion scoring) and microscopic analysis of oocyst morphology (Kumar et al. 2014). However, the relative complexity and requirement of expertise for these methods necessitated the development of molecular alternatives, including genus- and species-specific polymerase chain reaction (PCR) assays (Lew et al. 2003). The use of nuclear and mitochondrial genetic markers (e.g. internal transcribed spacer [ITS] sequences, 18S ribosomal RNA, cytochrome oxidase subunit I [COI]) has proven effective in the identification and taxonomic classification of protozoan parasites, including Eimeria (Kumar et al. 2015a; Ogedengbe et al. 2018; Tan et al. 2017).

Thus, ITS-1 sequences have served as genetic markers to identify Eimeria species (Cook et al. 2010; Oliveira et al. 2011). Based on the observed diversity, ITS-based speciesspecific primers have been developed for use in the identification of Eimeria species (Lew et al. 2003). However, studies from various countries have reported nucleotide variations in the ITS-1 region within Eimeria species isolates (Bhaskaran et al. 2010; Kumar et al. 2015a; Lew et al. 2003). Genetic diversity among species and strains of Eimeria could pose a major risk to the control of coccidiosis in the future. As such, knowledge defining naturally occurring genetic diversity becomes imperative to understand the pathogenicity and epidemiology of Eimeria that infect chickens (Morris \& Gasser 2006).

There is a dearth of information on Eimeria occurrence and diversity in South Africa. As such, reports on circulating Eimeria species in KwaZulu-Natal province together with information on their occurrence in commercial chickens are not available. This study, therefore, aimed to determine prevalence and genetic diversity of Eimeria species in both broiler and free-range chickens in KwaZulu-Natal province.

\section{Materials and methods Study area}

KwaZulu-Natal is the second most populous province among the nine provinces in South Africa. It has a population of approximately 10 million people and land size of $94000 \mathrm{~km}^{2}$ located between latitude $28^{\circ} 99^{\prime} \mathrm{S}$ and longitude $30^{\circ} 97^{\prime} \mathrm{E}$. The capital city of Pietermaritzburg has a warm and subtropical climate throughout the year, especially around the coastline, but gets colder in the inland areas. The poultry industry in KwaZulu-Natal province is one of the producers of broiler birds in South Africa with a total of 6.7 million broiler birds in 2017, contributing $6.4 \%$ to the national broiler production (South African Poultry Association 2017).

\section{Sample collection}

A total of 342 chicken faecal samples were collected from 12 broiler farms consisting of 41 pens ( $1-5$ pens per farm) and free-range chickens. The age of broiler chickens at the time of sampling ranged from 3 to 10 weeks, with the exception of a single farm consisting of 12-week-old chickens. In addition, 42 faecal samples of 40 free-ranging 3-week-old village chickens were randomly collected from four localities. The 342 samples were collected randomly once from the following locations: Pietermaritzburg, Phoenix, Scottburg, Stanger, Chatsworth, Westville, Maphumulo, Umvoti, Port Sherpstone and Shongweni of KwaZulu-Natal province from January to October 2018. Detailed information on the number of pens per farm, number of samples per pen, number of farms per location and number of chickens per location is shown in Appendix 1 Tables 1-A1 and 2-A1. There were no clinical signs of coccidiosis among the chickens on any of the farms sampled. Samples were collected following the procedure described by Kumar et al. (2014). Briefly, in the broiler farms, faecal samples were collected following a pre-determined ' $W$ ' pathway in each pen to allow random sampling. Fifty-millilitre conical tubes containing $10 \mathrm{~mL}$ of $2 \%$ potassium dichromate were used to collect faeces up to $20 \mathrm{~mL}$ of the tube and stored at $4{ }^{\circ} \mathrm{C}$ until further use. Depending on the size of the pen, four to eight 50-mL conical tubes of faecal samples were collected per pen and the content was mixed together vigorously.

\section{Sample processing and microscopic oocyst identification}

Samples were processed based on the procedures described by Kumar et al. (2014), with minor modifications. Two grams of faecal samples were weighed into a beaker and mixed with $100 \mathrm{~mL}$ of distilled water. This was stirred with a glass rod and later filtered through a gauze. The filtrate was transferred into a new 50-mL conical tube and filled to the brim with saturated salt solution. This was then centrifuged at $800 \times \mathrm{g}$ for 10 minutes. The supernatant was decanted and the sediment was transferred into a new $50-\mathrm{mL}$ tube and then later pelleted at $14000 \times \mathrm{g}$ for $3 \mathrm{~min}$. Oocysts per gram $(\mathrm{OPG})$ were counted using a McMaster counting chamber following a standard protocol (Haug, Williams \& Larsen 2006). Samples with OPG greater or equal to 250 OPG were selected for deoxyribonucleic acid (DNA) extraction. Photomicrograph images of unsporulated oocysts were taken randomly from each farm sampled using an OMAX compound microscope containing a $5 \mathrm{MP}$ camera at $400 \times$.

\section{DNA extraction}

Total genomic DNA was extracted using a Quick-DNA ${ }^{\mathrm{TM}}$ Fecal/Soil Microbe Miniprep Kit (Zymo Research, United States [US]) based on the manufacturer's protocol with minor modifications. Faecal samples in the Bashing Beads ${ }^{\mathrm{TM}}$ lysis tube $(0.1 \mathrm{~mm}$ and $0.5 \mathrm{~mm})$ were processed on a Vortex Genie at maximum speed for $25 \mathrm{~min}$, instead of $20 \mathrm{~min}$ as recommended by the manufacturer's protocol. DNA quality and concentration were checked on an agarose gel (1.5\%) and Nanodrop ${ }^{\mathrm{TM}} 1000$ spectrophotometer (Thermo Scientific, US) at $260 \mathrm{~nm}$ absorbance. 


\section{Polymerase chain reaction amplification}

A nested PCR protocol targeting the genomic ITS-1 region was used to detect each Eimeria species. Genus- and speciesspecific primers were used as described by Lew et al. (2003). Each $25 \mu \mathrm{L}$ PCR contained $12.5 \mu \mathrm{L} 2 \mathrm{X}$ DreamTaq Green PCR Master Mix (Thermo Scientific, US), $1 \mu \mathrm{L}$ of each forward and reverse primer $(10 \mu \mathrm{M}$ of stock solution; Table 1), $5.5 \mu$ L nuclease free water and $5 \mu \mathrm{L}$ DNA template. Thermal cycling was done as follows: initial denaturation at $94{ }^{\circ} \mathrm{C}$ for $3 \mathrm{~min}, 30$ cycles of $94{ }^{\circ} \mathrm{C}$ for $30 \mathrm{~s}, 56{ }^{\circ} \mathrm{C}$ for 30 seconds and $72{ }^{\circ} \mathrm{C}$ for $90 \mathrm{~s}$ and a final extension at $72{ }^{\circ} \mathrm{C}$ for $15 \mathrm{~min}$. The primary PCR product $(1 \mu \mathrm{L}$ of the $25 \mu \mathrm{L})$ was used as template for the nested PCR containing speciesspecific primers in each tube. The same thermal cycling conditions were used for the species with varying annealing temperature as follows: $55^{\circ} \mathrm{C}$ for $\mathrm{E}$. mitis, $56.7^{\circ} \mathrm{C}$ for E. tenella, $61{ }^{\circ} \mathrm{C}$ for E. acervulina, $62^{\circ} \mathrm{C}$ for E. maxima, $61^{\circ} \mathrm{C}$ for E. necatrix, $61^{\circ} \mathrm{C}$ for E. praecox and $61^{\circ} \mathrm{C}$ for E. brunetti. Nuclease-free water replaced the DNA template for the negative control. Amplification of nested PCR products was checked on $1.5 \%(\mathrm{w} / \mathrm{v})$ agarose gel at $100 \mathrm{~V}$ for $30 \mathrm{~min}$ and visualised under ultraviolet light using a Bio-Rad ChemiDoc $^{\mathrm{TM}}$ MP System (Bio-Rad, US). Similarly, the samples were also screened for the presence of three cryptic Eimeria OTUs by targeting the ITS-2 genomic region using the primers and thermal cycling procedure described by Fornace et al. (2013), as shown in Table 2. The PCR products were sent for sequencing at Inqaba Biotech (South Africa). Sequencing was done with both forward and reverse primers using Big Dye chemistries in an ABI 3500XL Genetic Analyzer, POP-7 ${ }^{\mathrm{TM}}$ (Thermo Scientific, US).

\section{Sequence analysis}

A total of 28 ITS-1 sequences were viewed, edited and trimmed. Consensus sequences were generated from both forward and reverse sequences using BioEdit version 7.0.5.3 software (Hall 1999). The sequences were submitted to National Center Biotechnology Information and assigned accession numbers (Appendix 1 Table 3-A1). Also, the sequences were compared with selected published sequences from the GenBank. Sequence alignment was performed using the ClustalW programme. Pairwise percentage identity (Appendix 1 Figure 1-A1) was carried using Sequence Demarcation Tool (SDT) version 1.2 software (Muhire, Varsani \& Martin 2014). Genetic distance within Eimeria species isolates from this study was calculated with MEGA version 6.0 (Tamura et al. 2013) using the Tamura 3-parameter model.

\section{Phylogenetic analysis of internal transcribed spacer-1 sequences}

The genetic diversity that exists between the ITS- 1 sequences generated in this study $(n=28)$ and those of American, Chinese, Indian, Australian, Egypt, Sudan and Swedish

TABLE 1: Genus- and species-specific internal transcribed spacer-1 primers used in the study.

\begin{tabular}{|c|c|c|c|c|}
\hline Genus-species & Primer strand & Primers & Annealing temperature $\left({ }^{\circ} \mathrm{C}\right)$ & Length (bp) \\
\hline \multirow[t]{2}{*}{ Eimeria genus } & Forward & AAGTTGCGTAAATAG AGCCCTC & 56.0 & Variable \\
\hline & Reverse & AGACATCCATTGCTG AAAG & & \\
\hline \multirow[t]{2}{*}{ Eimeria tenella } & Forward & AATTTAGTCCATCGC AACCCT & 56.7 & 278 \\
\hline & Reverse & CGAGCGCTCTGCATA CGACA & & \\
\hline \multirow[t]{2}{*}{ Eimeria acervulina } & Forward & GGC TTGGATGATGTT TGCTG & 61.0 & 321 \\
\hline & Reverse & CGAACGCAATAACAC ACGCT & & \\
\hline Eimeria brunetti & Reverse & TGGTCT TCCGTACGT CGGAT & & \\
\hline \multirow[t]{2}{*}{ Eimeria maxima } & Forward & CTACACCACTCAC AATGAGGCAC & 62.0 & 145 \\
\hline & Reverse & GTGATATCGTTCTG GAGAAGTT TGC & & \\
\hline \multirow[t]{2}{*}{ Eimeria mitis } & Forward & GGGTTTATTTCCTGT CCGTCGTCTC & 55.0 & 328 \\
\hline & Reverse & GCAAGAGAGAATCGG AATGCC & & \\
\hline \multirow[t]{2}{*}{ Eimeria praecox } & Forward & CCAAGCGATTTCATC ATTCGGGGAG & 61.0 & 116 \\
\hline & Reverse & AAAAGCAACAGCGA TTCAAG & & \\
\hline Eimeria necatrix & Reverse & GGCATACTAGCTTCG AGCAAC & & \\
\hline
\end{tabular}

Source: Lew, A.E., Anderson, G.R., Minchin, C.M., Jeston, P.J. \& Jorgensen, W.K., 2003, 'Inter-and intra-strain variation and PCR detection of the internal transcribed spacer 1 (ITS-1) sequences of Australian isolates of Eimeria species from chickens', Veterinary Parasitology 112(1-2), 33-50. https://doi.org/10.1016/S0304-4017(02)00393-X

Primers were all designed by Lew et al. (2003).

TABLE 2: Primers used for the detection of three cryptic Eimeria operational taxonomic units.

\begin{tabular}{lllc}
\hline Species & Primer ref & Primer sequences & Annealing temperature ( $\left.{ }^{\circ} \mathrm{C}\right)$ \\
\hline OTUx & OTU_X_f1 & Size (bp) & 56 \\
& OTU_X_r1 & GTGGTGTCGTCTGCGCGT & 133 \\
OTUy & OTU_Y_f1 & ACCACCGTATCTCTTTCGTGA & 56 \\
& OTU_Y_r1 & CAAGAAGTACACTACCACAGCATG & \\
OTUz & OTU_Z_f1 & ACTGATTTCAGGTCTAAAACGAAT & \\
& OTU_Z_r1 & TATAGTTTCTTTTGCGCGTTGC & 56 \\
\hline
\end{tabular}

Source: Lew, A.E., Anderson, G.R., Minchin, C.M., Jeston, P.J. \& Jorgensen, W.K., 2003, 'Inter-and intra-strain variation and PCR detection of the internal transcribed spacer 1 (ITS-1) sequences of Australian isolates of Eimeria species from chickens', Veterinary Parasitology 112(1-2), 33-50. https://doi.org/10.1016/S0304-4017(02)00393-X

Primers were all designed by Fornace et al. (2013).

OTUs, operational taxonomic units; bp, base pair. 
Eimeria species isolates published in GenBank (Appendix 1 Table 4-A1) were analysed. Phylogenetic analyses using the maximum likelihood (ML) method were carried out with MEGA version 6.0 (Tamura et al. 2013). The nucleotide substitution model that best fitted the data set was identified using Model-Test in MEGA6. Based on the Akaike Information Criterion, the Jukes-Cantor model was identified as the best model. Gaps in the alignment were treated as missing characters. Bootstrap iteration was based on 1000 replicates and the percentage value was indicated at each node. Neospora caninum (GenBank accession number: AF038860.1) and Toxoplasma gondii (EU025025.1) were used as out-group species to root the tree.

\section{Statistical analysis}

Data generated were analysed using the Statistical Package for the Social Sciences (SPSS) software version 25.0. Descriptive statistics were used to determine the prevalence of detected Eimeria species.

\section{Ethical consideration}

The protocol for this study was approved by the University of KwaZulu-Natal Animal Research Ethics Committee and assigned the reference number AREC/058/017D.

\section{Results}

\section{Polymerase chain reaction amplification and microscopic unsporulated oocyst detection}

Among broiler and free-ranging chickens, 19 out of 41 pens (46.3\%) and 25 out of 42 samples (59.5\%) were positive for Eimeria infection (Figure 1). The highest level of Eimeria infection was observed in the following locations in both broiler and free-ranging chickens as shown in Figure 2: Phoenix $(7 / 41 ; 17.1 \%)$, Scottburg $(4 / 41 ; 9.8 \%)$, Shongweni $(8 / 42 ; 19 \%)$, Port Sherpstone $(7 / 42 ; 16.7 \%)$ and Maphumulo $(7 / 42 ; 16.7 \%)$.

Using the species-specific nested PCR assay, five Eimeria species were identified (E. tenella, E. maxima, E. acervulina, E. brunetti and E. mitis) in all screened samples (Figure 3). In broiler farms, E. tenella had the highest prevalence (13/19; $68.4 \%)$, followed by E. maxima $(9 / 19 ; 47.4 \%)$ based on pens

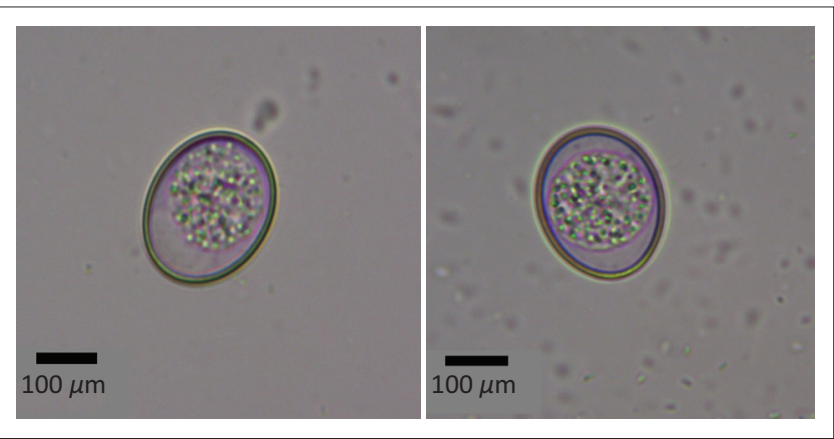

FIGURE 1: Images of unsporulated Eimeria oocysts detected in faecal samples from infected farms. which were positive. However, in free-ranging chickens, E. mitis $(24 / 25 ; 96 \%)$ and E. maxima $(23 / 25 ; 92 \%)$ had the

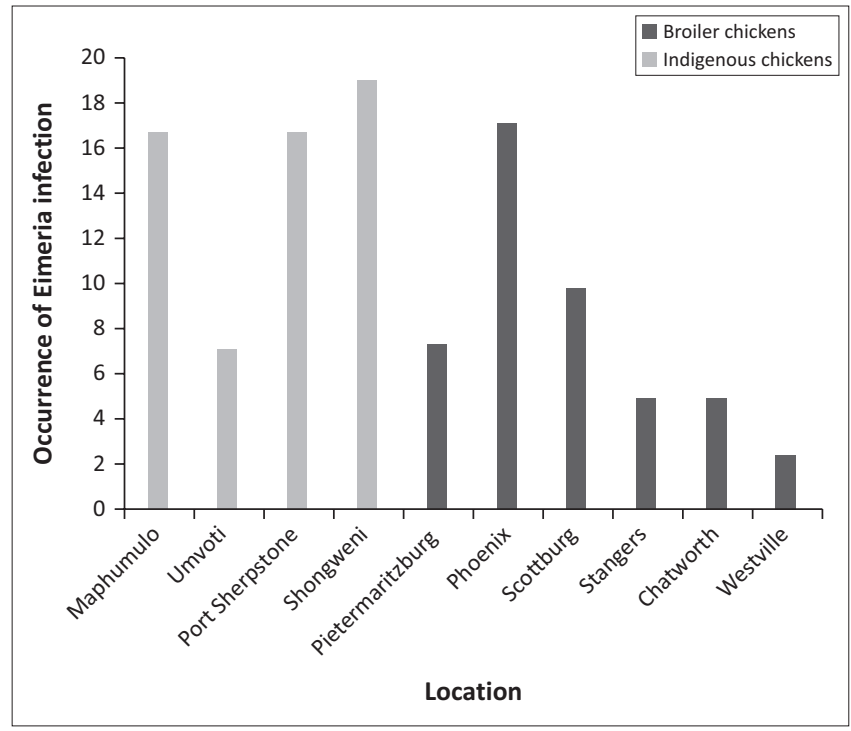

FIGURE 2: Occurrence of Eimeria infection in different locations in KwaZulu-Natal.
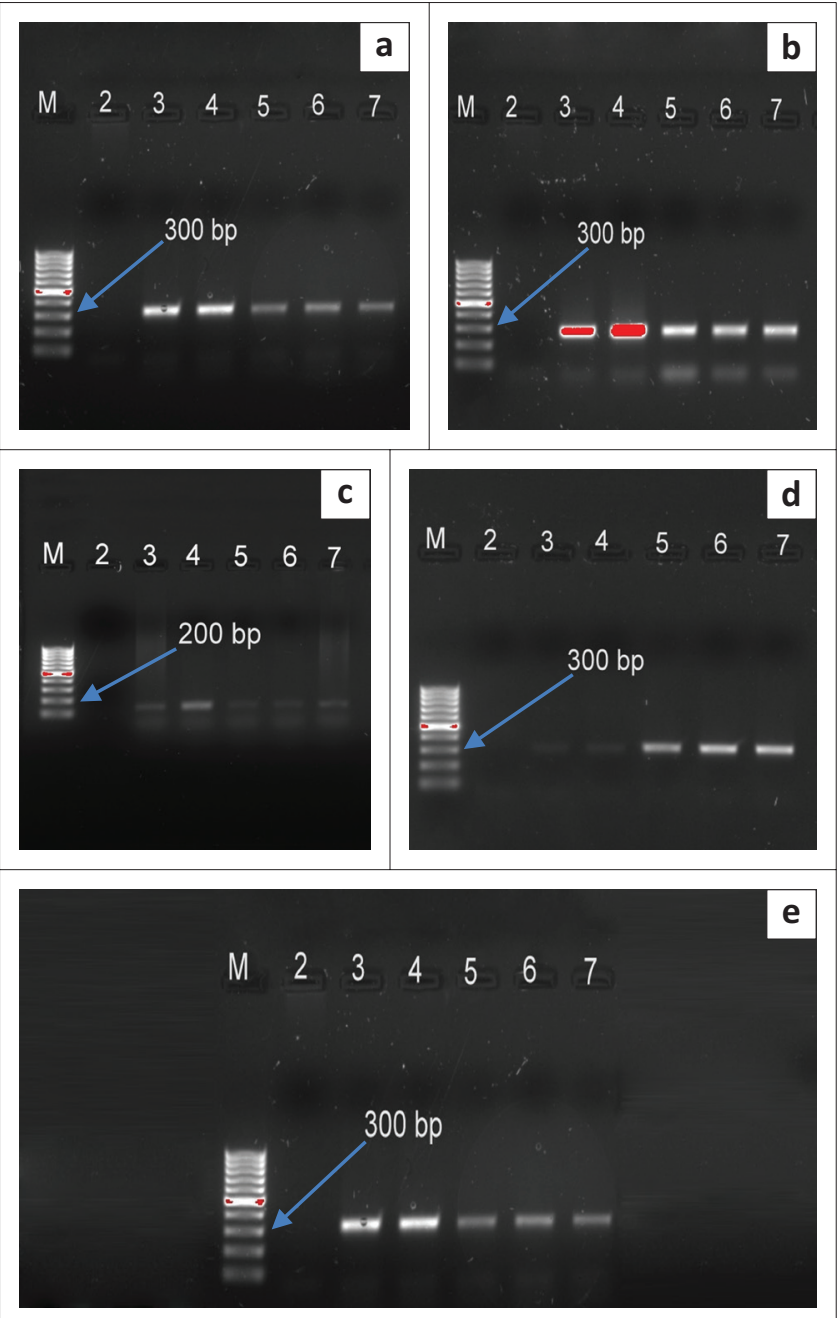

bp, base pairs

FIGURE 3: Amplification of Eimeria species by polymerase chain reaction. M: 100 bp DNA marker; L2: negative control; L3-7: samples. (a) Eimeria mitis 328 bp; (b) Eimeria tenella 278 bp; (c) Eimeria maxima 145 bp; (d) Eimeria acervulina $321 \mathrm{bp}$; (e) Eimeria brunetti $311 \mathrm{bp}$. 
highest prevalence. The lowest prevalence was observed for E. acervulina $(5 / 19 ; 26.3 \%)$ and E. brunetti $(3 / 25 ; 12 \%)$ in broiler and free-ranging chickens, respectively (Figure 4 ).

\section{DNA amplification of Eimeria species}

The most common mixed species combinations detected in broiler and free-ranging chicken faecal samples were E. tenella + E. maxima $(4 / 19 ; 21.1 \%)$ and E. mitis + E. maxima + E. acervulina $(11 / 25 ; 44 \%)$, respectively. Other combinations were E. mitis + E. maxima $(2 / 19 ; 10.5 \%)$, E. tenella + E. mitis $(1 / 25 ; 4 \%)$, E. aceroulina + E. maxima $(1 / 25 ; 4 \%)$, E. aceroulina + E. tenella $(2 / 19 ; 10.5 \%)$, E. mitis + E. tenella $(3 / 19 ; 15.8 \%)$, E. aceroulina + E. tenella + E. maxima $(1 / 19 ; 5.3 \%)$, E. acervulina + E. mitis + E. tenella $(2 / 19 ; 10.5 \%)$, E. tenella + E. aceroulina + E. mitis + E. maxima $(7 / 25 ; 28 \%)$, E. tenella + E. mitis + E. brunett $i+$ E. maxima $(1 / 25 ; 4 \%)$, E. aceroulina + E. mitis + E. tenella + E. maxima $(3 / 19 ; 15.8 \%)$ and E. tenella + E. acervulina + E. mitis + E. maxima + E. brunetti $(2 / 25 ; 8 \%)$. Overall, among the broiler farms, Scottburg farm had the highest prevalence level of mixed species (E. acervulina + E. mitis + E. tenella + E. maxima; $75 \%$ ), whilst mixed species (E. acervulina + E. mitis + E. maxima) with a prevalence of $44 \%$ was the highest among all locations with the free-range chickens. Cryptic Eimeria OTUs were not detected in all the samples screened.

\section{Internal transcribed spacer-1 sequence analysis}

Internal transcribed spacer-1 sequences of E. mitis, E. maxima, E. tenella, E. aceroulina and E. brunetti from this study showed high homology with sequences from Eimeria species present in the GenBank as follow: $90 \%-93 \%$ identity for E. mitis, $99.31 \%$ for E. maxima, $99 \%$ - 100\% for E. tenella, $99.38 \%$ for E. aceroulina and $100 \%$ for E. brunetti. The overall mean genetic distance within Eimeria species isolates from KwaZulu-Natal in South Africa calculated by ML (Tamura 3-parameter model) with 1000 bootstrap replicates was $1.14 \pm$ 0.08 . Mean genetic distance per species was as follows: $E$. mitis $(0.13 \pm 0.014)$, E. maxima $(0.09 \pm 0.020)$, E. tenella $(0.09 \pm 0.012)$ E. acervulina $(0.02 \pm 0.005)$ and E. brunetti $(0.02 \pm 0.006)$.

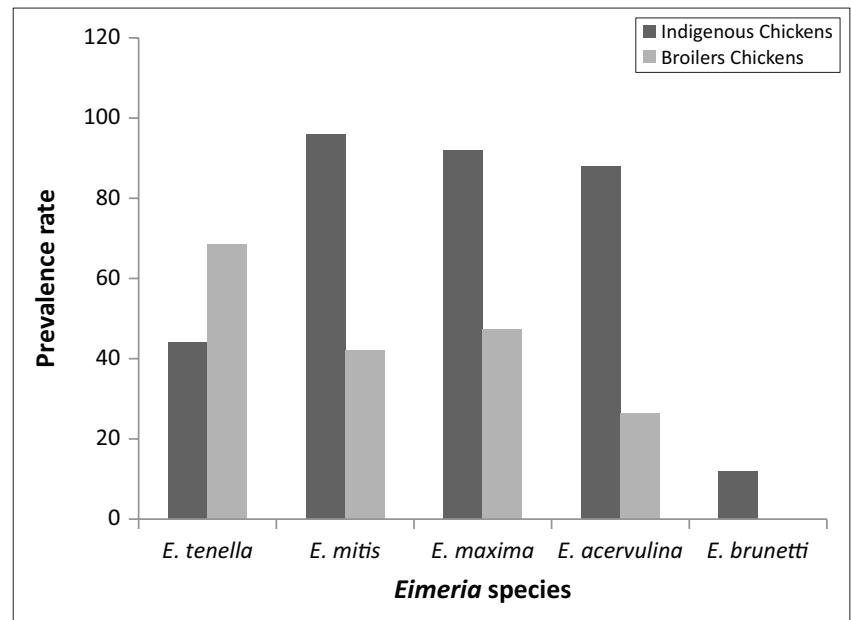

E. maxima, Eimeria maxima; E. acervulina, Eimeria acervulina; E. mitis, Eimeria mitis, E. brunette, Eimeria brunette; E. tenella, Eimeria tenella.

FIGURE 4: Prevalence of Eimeria species in both broilers and free-range chickens in KwaZulu-Natal.

\section{Phylogenetic analysis of internal transcribed spacer-1 sequences}

Maximum likelihood with the Jukes-Cantor model was used to create the phylogenetic tree (Figure 5) of the 28 ITS- 1 sequences generated in this study, together with reference Eimeria ITS-1 sequences of American, Chinese, Indian, Australian and Swedish isolates. Irrespective of their geographical locations, the ITS- 1 sequences of all five species clustered in distinct clades. Among the E. tenella clade, all the seven E. tenella sequences from this study clustered with E. tenella sequences from China, Egypt and India with a very strong support. Similarly, all the five and eight sequences of E. acervulina and E. mitis from this study, respectively, clustered with E. acervulina and E. mitis sequences of America,

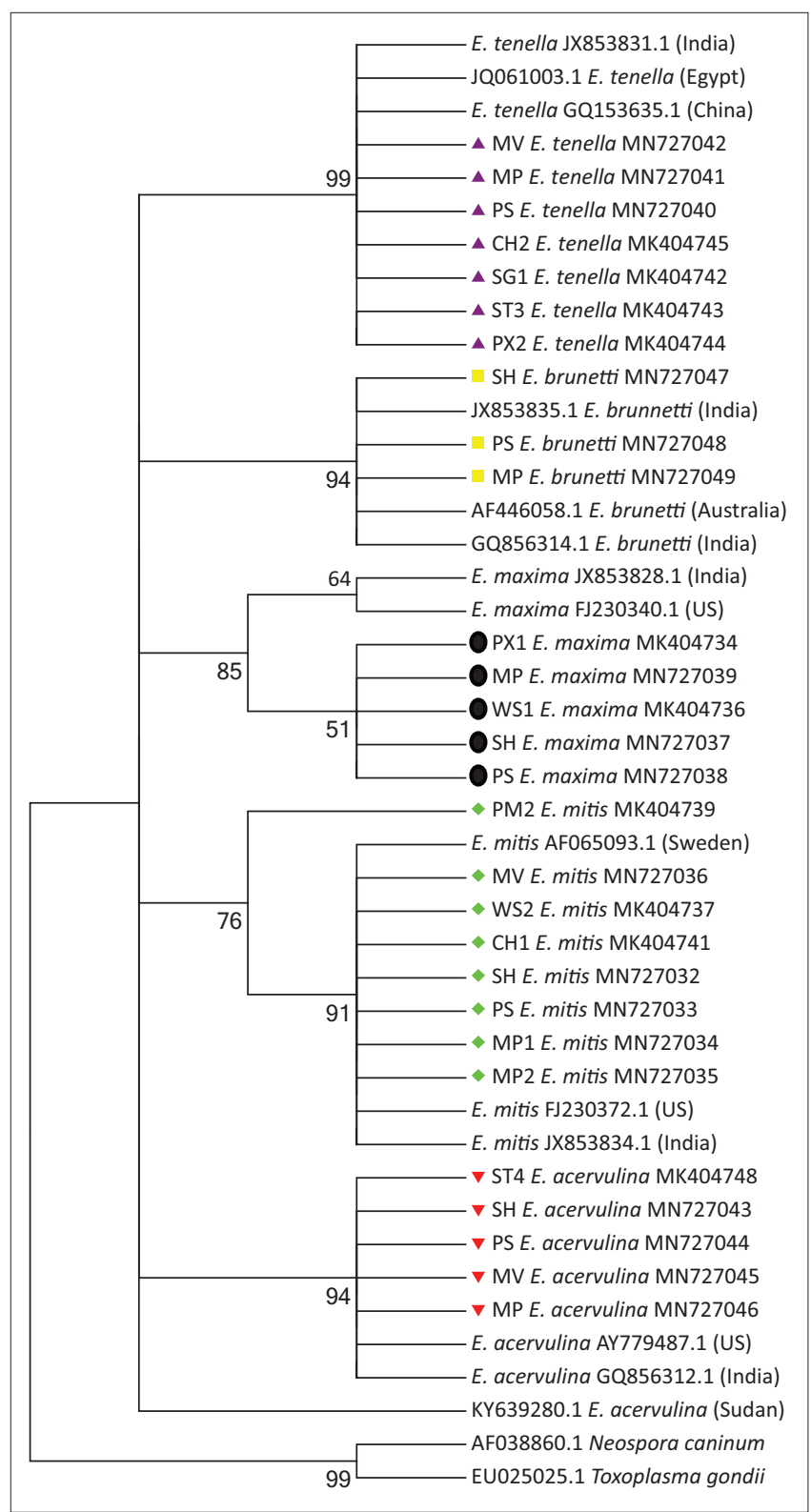

E. maxima, Eimeria maxima; E. acervulina, Eimeria acervulina; E. mitis, Eimeria mitis; E. brunette, Eimeria brunette; E. tenella, Eimeria tenella; US, United States.

FIGURE 5: Maximum likelihood tree (Tamura-3 model) of internal transcribed spacer-1 sequences of Eimeria species. Percentage of bootstrap (1000 replicate) values is indicated in each node. The scale bar indicates sequence substitution per site. Sequences in this study are in different colours and shapes. 
India, Sudan and Sweden with a very strong support. All the E. maxima sequences from this study clustered with E. maxima sequences from America and India with low support. Within the E. brunetti clade, all the three sequences from this study clustered with E. brunetti sequences from India and Australia with a very strong support. Genetic distances between ITS-1 sequences of Eimeria isolates in this study and those of a public database were as follow: E. mitis $(0.12 \pm 0.013)$, E. acervulina $(0.02 \pm 0.005)$, E. maxima $(0.07 \pm 0.016)$, E. tenella $(0.07 \pm 0.010)$ and E. brunetti $(0.01 \pm 0.004)$.

\section{Discussion}

Coccidiosis is an enteric disease that poses a threat to efficient poultry production (Ogedengbe, Hanner \& Barta 2011), compromising economic productivity and chicken welfare. For effective diagnosis, control and epidemiology of the disease, the identification of specific species of Eimeria is essential. Understanding the occurrence of genetic diversity and regional population structure are important (Hamza, Al-Massodi \& Jeddoa 2015; Morris \& Gasser 2006).

In this study, Eimeria infection had an overall prevalence of $46.3 \%$ (19 out of 41 pens) and $59.5 \%$ (25 out of 42 samples) across different farms and locations, which was higher than the $29.4 \%$ found among Eimeria parasites from KwaZuluNatal and Limpopo (Malatji et al. 2016). However, it was lower than previous reports from other regions including Ethiopia (56\%; Luu et al. 2013), Romania (91\%; Gyorke et al. 2013), Anhui Province, China (87.75\%; Huang et al. 2017) and two north Indian states (81.3\%; Kumar et al. 2015b).

Molecular diagnosis using nested species-specific ITS-1 primers was used to identify five species of Eimeria (E. tenella, E.maxima, E. acervulina, E. brunetti and E. mitis) circulating in both commercial broiler and free-range chickens in KwaZuluNatal province. This is similar to the study of DebbouIouknane, Benbarek and Ayad (2018), who reported the same five species of Eimeria among broilers farms in Bejaia region of Algeria. The prevalence of one or more species of Eimeria in broiler farms in this study could be influenced by the different anticoccidial used in various farms (Carvalho et al. 2011), although our study did not document anticoccidial use in the farms.

The most prevalent species among broiler farms in this study was E. tenella $(68.4 \%)$, which is in agreement with other studies that have reported a high prevalence that ranges from $80.67 \%$ to $100 \%$ in Anhui Province, China, Trinadad and Indonesia (Brown et al. 2018; Hamid et al. 2018; Huang et al. 2017). The high prevalence of E. tenella poses a major concern to the health status of chickens because it is associated with caecal lesions causing haemorrhage, oedema and anaemia (Iacob \& Duma 2009). However, E. mitis (96\%) had the highest prevalence among free-ranging village chickens in this study. The reason for this is unclear as it is contrary to reports of most studies where E. aceroulina and E. tenella are known to be highly prevalent in most farms because of their high reproductive potentials (Williams 2001).
Co-infection with multiple Eimeria species is a common finding in many poultry farms (Aarthi et al. 2010; Haug et al. 2008). We also found multiple infections (57.9\% and $100 \%$ ) to be common in both chicken types, with two or more species among the samples examined. Eimeria tenella + E. maxima $(21.1 \%)$ and E. mitis + E. maxima + E. acervulina $(44 \%)$ were the most common co-infections. This is in line with different studies which reported the frequency of E. maxima in most mixed species infection (Kaboudi, Umar \& Munir, 2016).

Mixed infections among Eimeria species poses a challenge to the control of coccidiosis in chickens as it can increase pathogenicity of the disease among birds (Jekins et al. 2008). It could also serve as a potential threat to the effectiveness of anticoccidial vaccine, and this has warranted the combination of different Eimeria strains in some species, such as E. maxima, in the design of anticoccidial vaccines.

The efficacy of anticoccidial vaccines is under threat, especially with the recent upsurge of new Eimeria variants (OTUs), which was first detected circulating among commercial birds in Australia (Cantacessi et al. 2008). The presence of these OTUs (OTUx, OTUy and OTUz) has also been reported across much of the Southern Hemisphere (Clark et al. 2016; Fornace et al. 2013; Jatau et al. 2016). In this study, none of the samples was positive for any of the three OTUs. This could be because of the geographical location of our study sample, which is on latitude $28^{\circ} \mathrm{S}$. Although a study has reported the distribution of these cryptic species (OTUs) in the northern hemisphere (Jatau et al. 2016), a more elaborate study by Clark et al. (2016) in 20 different countries from five continents has opined that these OTUs are distributed towards the south of the $30^{\circ} \mathrm{N}$ latitude. The study reported eight different countries to be populated with OTUs with the following distribution: OTUz was found in all the eight countries south of the $30^{\circ} \mathrm{N}$ latitude and OTUx was detected south of $30^{\circ} \mathrm{N}$ in six out of the eight countries, whilst OTUx, OTUy and OTUz were only detected in Nigeria among all the African countries at the same geographical location (Clark et al. 2016).

Similarly, ITS-1 sequences belonging to five different Eimeria species were generated in this study. The similarity of the sequences generated in this study when compared with published Eimeria species sequences ranged from $90 \%$ to $93 \%$ in E. mitis, $99.31 \%$ in E. maxima, $99 \%$ to $100 \%$ in E. tenella, $100 \%$ in E. brunetti and $99.38 \%$ in E. acervulina. Although the ML tree, as shown in Figure 5, grouped all five species of Eimeria into five distinct clades, some level of variation existed within species of Eimeria in this study and that of the public database, as indicated by their mean genetic distances. The lowest genetic distance of 0.01 was observed among E. brunetti isolates. Similar ITS- 1 sequence variations among E. mitis, E. tenella and E. maxima have also been reported by different authors (Bhaskaran et al. 2010; Kumar et al. 2015a; Lew et al. 2003; Thenmozhi, Veerakumari \& Raman 2014). 
In conclusion, this study characterised Eimeria species in broiler and free-range chickens based on molecular diagnostic techniques and determined their diversity in KwaZulu-Natal province. The study reports the presence of five Eimeria species (E. tenella, E. maxima, E. acervulina, E. brunetti and E. mitis), all of which are regarded as pathogenic. Although none of the chickens showed clinical signs of coccidiosis during sampling, the high prevalence of these pathogenic parasites in the study area suggests that subclinical infection is common in all infected chickens. Thus, effective control strategies remain imperative to curtail coccidial infection in poultry farms in the study areas. A survey on the types of anticoccidial used among commercial farms and their efficacy should be conducted to understand the impact of this disease. This will also help in the implementation of policies for the control of this disease in KwaZulu-Natal province.

\section{Acknowledgements}

Financial support by the National Research Foundation of South Africa (Grant numbers: 112886 and 112768) is gratefully acknowledged.

\section{Competing interests}

The authors have declared that no competing interest exists.

\section{Authors' contributions}

A.J.F. was involved in design, collection of samples, laboratory work, result analysis and manuscript writing. O.TZ. co-supervised the research and corrected the manuscripts. D.P.B. and S.O.P. were involved in grant writing for the research and correcting the manuscript. J.L. provided technical support and corrected the manuscript. S.M. provided guide for sample processing, assisted with sample collection and corrected the manuscript. M.A.A. conceived the idea, acquired funding for the research, supervised the research and corrected the manuscript.

\section{Funding information}

This research received no specific grant from any funding agency in the public, commercial or not-for-profit sectors.

\section{Data availability statement}

Data sharing is not applicable to this article as no new data was created or analysed in this study.

\section{Disclaimer}

The views and opinions expressed in this article are those of the authors and do not necessarily reflect the official policy or position of any affiliated agency of the authors.

\section{References}

Aarthi, S., Raj, G.D., Raman, M., Gomathinayagam, S. \& Kumanan, K., 2010, 'Molecular prevalence and preponderance of Eimeria spp. among chickens in Tamil Nadu,
India', Parasitology Research 107(4), 1013-1017. https://doi.org/10.1007/s00 India', Parasitology
Alders, R.G. \& Pym, R.A.E., 2009, 'Village poultry: Still important to millions, eight thousand years after domestication', World's Poultry Science Journal 65(2), 181-190. https://doi.org/10.1017/S0043933909000117

Bhaskaran, M.S., Venkatesan, L., Aadimoolam, R., Jayagopal, H.T. \& Sriraman, R., 2010, 'Sequence diversity of internal transcribed spacer-1 (ITS-1) region of Eimerio infecting chicken and its relevance in species identification from Indian field samples', Parasitology Research 106(2), 513. https://doi.org/10.1007/s00436samples',

Blake, D.P. \& Tomley, F.M., 2014, 'Securing poultry production from the ever-present Eimeria challenge', Trends in Parasitology 30(1), 12-19. https://doi.org/10.1016/j. pt.2013.10.003

Brown Jordan, A., Blake, D., Beard, J., Beharry, A., Serrette, L., Soleyn, A., et al., 2018, 'Molecular identification of Eimeria species in broiler chickens in Trinidad, West Indies', Veterinary Sciences 5(1), 12. https://doi.org/10.3390/vetsci5010012

Cantacessi, C., Riddell, S., Morris, G.M., Doran, T., Woods, W.G., Otranto, D. Gasser, R.B., 2008. 'Genetic characterisation of three unique operational taxonomic units of Eimeria from chickens in Australia based on nuclear spacer ribosomal DNA' Veterinary Parasitology 152(3-4), 226-234. https://doi.org/10.1016/j. Veterinary Parasito
vetpar.2007.12.028

Carvalho, F.S., Wenceslau, A.A., Teixeira, M. \& Albuquerque, G.R., 2011, 'Molecular diagnosis of Eimeria species affecting naturally infected Gallus gallus', Genetics and Molecular Research 10(2), 996-1005. https://doi.org/10.4238/vol10-2gmr1043

Clark, E.L., Macdonald, S.E., Thenmozhi, V., Kundu, K., Garg, R., Kumar, S., et al., 2016, 'Cryptic Eimeria genotypes are common across the southern but not northern hemisphere', International Journal for Parasitology 46(9), 537-544. https://doi. org/10.1016/j.ijpara.2016.05.006

Cook, S.M., Higuchi, D.S., McGowan, A.L., Schrander, J.S., Withanage, G.S.K. \& Francis, M.I. 2010, 'Polymerase chain reaction-based identity assay for pathogenic turkey Eimeria', Avian Diseases 54(4), 1152-1156. https://doi.org/10.1637/9271-020310-Reg.1

Debbou-louknane, N., Benbarek, H. \& Ayad, A., 2018, 'Prevalence and aetiology of coccidiosis in broiler chickens in Bejaia province, Algeria', Onderstepoort Journal of Veterinary Research 85(1), 1-6. https://doi.org/10.4102/ojvr.v85i1.1590

Fornace, K.M., Clark, E.L., Macdonald, S.E., Namangala, B., Karimuribo, E., Awuni, J.A., et al., 2013, 'Occurrence of Eimeria species parasites on small-scale commercial chicken farms in Africa and indication of economic profitability', PLoS One 8(12), e84254. https://doi.org/10.1371/journal.pone.0084254

Godwin, R.M. \& Morgan, J.A., 2015, 'A molecular survey of Eimeria in chickens across Australia', Veterinary Parasitology 214(1-2), 16-21. https://doi.org/10.1016/j. vetpar.2015.09.030

Györke, A., Pop, L. \& Cozma, V., 2013, 'Prevalence and distribution of Eimeria species in broiler chicken farms of different capacities', Parasite 20(50), 8. https://doi. org/10.1051/parasite/2013052

Hall, T.A., 1999, BioEdit: a user-friendly biological sequence alignment editor and analysis program for Windows $95 / 98 / \mathrm{NT}$. In Nucleic acids symposium series vol. 41, No. 41, pp. 95-98, Information Retrieval Ltd., London, January c1979-c2000, 1999.

Hamid, P.H., Kristianingrum, Y.P., Wardhana, A.H., Prastowo, S. \& Silva, L.M.R.D., 2018, 'Chicken coccidiosis in Central Java, Indonesia: A recent update', Veterinary Medicine International 2018(8515812), 7. https://doi.org/10.1155/2018/8515812

Hamza, D.M., Al-Massodi, R.H. \& Jeddoa, M.A., 2015, 'Molecular detection and discrimination of three poultry Eimeria species in Kerbala and Babylon provinces, Iraq', International Journal of Current Research and Review 7(11), 13.

Haug, A., Gjevre, A.G., Thebo, P., Mattsson, J.G. \& Kaldhusdal, M., 2008, 'Coccidial infections in commercial broilers: Epidemiological aspects and comparison of Eimeria species identification by morphometric and polymerase chain reaction techniques', Avian Pathology 37(2), 161-170. https://doi.org/10.1080/030794 50801915130

Haug, A., Williams, R.B. \& Larsen, S., 2006, 'Counting coccidial oocysts in chicken faeces: A comparative study of a standard McMaster technique and a new rapid method', Veterinary Parasitology 136(3-4), 233-242. https://doi.org/10.1016/j. vetpar.2005.11.024

Huang, Y., Ruan, X., Li, L. \& Zeng, M., 2017, 'Prevalence of Eimeria species in domestic chickens in Anhui province, China', Journal of Parasitic Diseases 41(4), 1014-1019. https://doi.org/10.1007/s12639-017-0927-1

lacob, O.C. \& Duma, V., 2009, 'Clinical, paraclinical and morphopathological aspects in cecal eimeriosis of broilers', Revista Scientia Parasitologica 10(1/2), 43-50.

Jatau, I.D., Salaiman, N,H., Musa, I.W., Lawal, A.I., Okubanjo, O.O. et al., 2016, 'Three operational taxonomic units of Eimeria are common in Nigerian chickens and may undermine effective molecular diagnosis of coccidiosis', BMC Veterinary Research 12(1), 86. https://doi.org/10.3923/ajpsaj.2012.79.88

Jenkins, M., Allen, P., Wilkins, G., Klopp, S. \& Miska, K., 2008, 'Eimeria praecox infection ameliorates effects of Eimeria maxima infection in chickens', Veterinary Parasitology 155(1-2), 10-14. https://doi.org/10.1016/j.vetpar.2008.04.013

Kaboudi, K., Umar, S. \& Munir, M.T., 2016, 'Prevalence of coccidiosis in free-range chicken in Sidi Thabet, Tunisia', Scientifica 2016(7075195), 6. https://doi.org/10. 1155/2016/7075195

Kumar, S., Garg, R., Banerjee, P.S. Ram, H. Kundu, K., \& Kumar, S. et al. 2015a 'Genetic diversity within ITS-1 region of Eimeria species infecting chickens of 'Genth India', Infection, Genetics and Evolution 36, 262-267. https://doi. north India', Infection, Genetics
org/10.1016/j.meegid.2015.09.023

Kumar, S., Garg, R., Ram, H., Maurya, P.S. \& Banerjee, P.S, 2015b, 'Gastrointestinal parasitic infections in chickens of upper gangetic plains of India with special reference to poultry coccidiosis', Journal of Parasitic Diseases 39(1), 22-26. https://doi.org/10.1007/s12639-013-0273-x 
Kumar, S., Garg, R., Moftah, A., Clark, E.L., Macdonald, S.E., Chaudhry, A.S. et al. 2014, 'An optimised protocol for molecular identification of Eimeria from chickens', Veterinary optimised protocol for molecular identification of Eimeria from chickens', Veter.
Parasitology 199(1-2), 24-31. https://doi.org/10.1016/j.vetpar.2013.09.026

Lew, A.E., Anderson, G.R., Minchin, C.M., Jeston, P.J. \& Jorgensen, W.K., 2003, 'Inter-and intra-strain variation and PCR detection of the internal transcribed spacer 1 (ITS-1) sequences of Australian isolates of Eimeria species from chickens', Veterinary Parasitology 112(1-2), 33-50. https://doi.org/10.1016/S0304-4017(02)00393-X

Luu, L., Bettridge, J., Christley, R.M., Melese, K., Blake, D., Dessie, T. et al., 2013, Prevalence and molecular characterisation of Eimeria species in Ethiopian village chickens', BMC Veterinary Research 9(1), 208. https://doi.org/10.1186/1746-6148-9-208

Malatji, D.P., Tsotetsi, A.M., van Marle-Köster, E. \& Muchadeyi, F.C., 2016, 'A description of village chicken production systems and prevalence of gastrointestinal parasites: Case studies in Limpopo and KwaZulu-Natal provinces of South Africa', Onderstepoort Journal of Veterinary Research 83(1), 1-8. https:// doi.org/10.4102/ojvr.v83i1.968

Morris, G.M. \& Gasser, R.B., 2006, 'Biotechnological advances in the diagnosis of avian coccidiosis and the analysis of genetic variation in Eimeria', Biotechnology Advances 24(6), 590-603. https://doi.org/10.1016/j.biotechadv.2006.06.001

Muhire, B.M., Varsani, A. \& Martin, D.P., 2014, 'SDT: A virus classification tool based on pairwise sequence alignment and identity calculation', PLoS One 9(9), e108277. https://doi.org/10.1371/journal.pone.0108277

Nematollahi, A., Moghaddam, G.H. \& Niyazpour, F., 2008, 'Prevalence of Eimeria spp. among broiler chicks in Tabriz (Northwest of Iran)', Research Journal of Poultry Science 2(3), 72-74.

Ogedengbe, J.D., Hanner, R.H. \& Barta, J.R., 2011, 'DNA barcoding identifies Eimeria species and contributes to the phylogenetics of coccidian parasites (Eimeriorina, Apicomplexa, Alveolata)', International Journal for Parasitology 41(8), 843-850. https://doi.org/10.1016/j.ijpara.2011.03.007
Ogedengbe, M.E., El-Sherry, S., Ogedengbe, J.D., Chapman, H.D. \& Barta, J.R., 2018, 'Phylogenies based on combined mitochondrial and nuclear sequences conflict with morphologically defined genera in the eimeriid coccidia (Apicomplexa)', International Journal for Parasitology 48(1), 59-69. https://doi.org/10.1016/j. ijpara.2017.07.008

Oliveira, U.C., Fraga, J.S., Licois, D., Pakandl, M. \& Gruber, A., 2011, 'Development of molecular assays for the identification of the 11 Eimeria species of the domestic rabbit (Oryctolagus cuniculus)', Veterinary Parasitology 176(2-3), 275-280. https://doi.org/10.1016/j.vetpar.2010.10.054

South African Poultry Association, 2017, Distribution of chickens in South Africa, viewed 09 April 2019, from www.sapoultry.co.za.

Tamura, K., Peterson, D., Stecher, G., Filipski, A. \& Kumar, S., 2013, 'MEGA6: Molecular evolutionary genetic analysis version 6.0. Molecular Biology and Evolution 30(12) 2725-2729. https://doi.org/10.1093/molbev/mst197

Tan, L., Li Y., Yang, X., Ke, Q., Lei, W., Mughal, M.N. et al. 2017, 'Genetic diversity and drug sensitivity studies on Eimeria tenella field isolates from Hubei Province of China', Parasites \& Vectors 10(1), 137. https://doi.org/10.1186/s13071-0172067-y

Thenmozhi, V., Veerakumari, L. \& Raman, M., 2014, 'Preliminary genetic diversity study on different isolates of Eimeria tenella from South India', Internationa Journal of Advanced Veterinary Science and Technology 3(1), 114-118. https:// doi.org/10.23953/cloud.ijavst.194

Williams, R.B., 2001, 'Quantification of the crowding effect during infections with the seven Eimeria species of the domesticated fowl: Its importance for experimental designs and the production of oocyst stocks', International Journal for Parasitology 31(10), 1056-1069. https://doi.org/10.1016/S00207519(01)00235-1 


\section{Appendix 1}

TABLE 1-A1: Summary of samples collected in broiler farms and the outcome of Eimeria detection.

\begin{tabular}{|c|c|c|c|c|c|}
\hline Location & Farms & No of pen per farm & No of sample per farm & Age (Weeks) & Positive pen \\
\hline \multirow[t]{2}{*}{ Pietermaritzburg } & $A$ & 5 & 40 & 3 & 0 \\
\hline & B & 3 & 41 & 4 & 3 \\
\hline \multirow[t]{3}{*}{ Phoenix } & C & 4 & 20 & 3 & 4 \\
\hline & $\mathrm{D}$ & 3 & 15 & 4 & 2 \\
\hline & $\mathrm{E}$ & 3 & 15 & 4 & 1 \\
\hline Scottburgh & $\mathrm{F}$ & 4 & 25 & 4 & 4 \\
\hline \multirow[t]{3}{*}{ Stanger } & G & 5 & 48 & 9 & 0 \\
\hline & $\mathrm{H}$ & 4 & 22 & 10 & 1 \\
\hline & 1 & 3 & 15 & 9 & 1 \\
\hline \multirow[t]{2}{*}{ Chatsworth } & J & 3 & 28 & 10 & 1 \\
\hline & K & 1 & 7 & 9 & 1 \\
\hline Westville & $\mathrm{L}$ & 3 & 24 & 12 & 1 \\
\hline Total & 12 & 41 & 300 & & 19 \\
\hline
\end{tabular}

TABLE 2-A1: Summary of samples collected in free-range chickens and the outcome of Eimeria infection.

\begin{tabular}{lccc}
\hline Location & No of chicken & No of sample per location & No of positive samples \\
\hline Maphumulo & 10 & 10 & 7 \\
Umvoti & 10 & 10 & 3 \\
Port Sherpstone & 10 & 7 & 7 \\
Shongweni & 10 & $\mathbf{4 2}$ & 8 \\
\hline Total & $\mathbf{4 0}$ & $\mathbf{2 5}$ \\
\hline
\end{tabular}

TABLE 3-A1: ITS-1 sequences of Eimeria species generated from this study.

\begin{tabular}{|c|c|c|c|}
\hline Serial No & Sequence ID & Species & GenBank accession no. \\
\hline 1 & PX1 & Eimeria maxima & MK404734 \\
\hline 2 & WS1 & Eimeria maxima & MK404736 \\
\hline 3 & WS2 & Eimeria mitis & MK404737 \\
\hline 4 & PM2 & Eimeria mitis & MK404739 \\
\hline 5 & $\mathrm{CH} 1$ & Eimeria mitis & MK404741 \\
\hline 6 & SG1 & Eimeria tenella & MK404742 \\
\hline 7 & ST3 & Eimeria tenella & MK404743 \\
\hline 8 & PX2 & Eimeria tenella & MK404744 \\
\hline 9 & $\mathrm{CH} 2$ & Eimeria tenella & MK404745 \\
\hline 10 & ST4 & Eimeria acervulina & MK404748 \\
\hline 11 & $\mathrm{SH}$ & Eimeria mitis & MN727032 \\
\hline 12 & PS & Eimeria mitis & MN727033 \\
\hline 13 & MP1 & Eimeria mitis & MN727034 \\
\hline 14 & MP2 & Eimeria mitis & MN727035 \\
\hline 15 & MV & Eimeria mitis & MN727036 \\
\hline 16 & $\mathrm{SH}$ & Eimeria maxima & MN727037 \\
\hline 17 & PS & Eimeria maxima & MN727038 \\
\hline 18 & MP & Eimeria maxima & MN727039 \\
\hline 19 & PS & Eimeria tenella & MN727040 \\
\hline 20 & MP & Eimeria tenella & MN727041 \\
\hline 21 & $\mathrm{MV}$ & Eimeria tenella & MN727042 \\
\hline 22 & $\mathrm{SH}$ & Eimeria acervulina & MN727043 \\
\hline 23 & PS & Eimeria acervulina & MN727044 \\
\hline 24 & MV & Eimeria acervulina & MN727045 \\
\hline 25 & MP & Eimeria acervulina & MN727046 \\
\hline 26 & $\mathrm{SH}$ & Eimeria brunetti & MN727047 \\
\hline 27 & PS & Eimeria brunetti & MN727048 \\
\hline 28 & MP & Eimeria brunetti & MN727049 \\
\hline
\end{tabular}

PX, Phoenix; WS, Westville; PMB, Pietermaritzburg; CH, Chatsworth; SG, Stanger; ST, Scottburg; PS, Port Sherpstone; MV, Umvoti; MP, Maphumulo; SH, Shongweni. 
TABLE 4-A1: ITS-1 sequences of Eimeria species downloaded from GenBank.

\begin{tabular}{llll}
\hline No & Species & GenBank accession number & Origin of isolates \\
\hline 1 & E. mitis & FJ230372.1 & America \\
2 & E. mitis & JX853834.1 & India \\
3 & E. mitis & AF065093.1 & Sweden \\
4 & E. maxima & JX853828.1 & India \\
5 & E. maxima & FJ230340.1 & America \\
6 & E. tenella & GQ153635.1 & China \\
7 & E. tenella & JX853831.1 & India \\
8 & E. tenella & JQ061003.1 & Egypt \\
9 & E. acervulina & AY779487.1 & America \\
10 & E. acervulina & GQ856312.1 & India \\
11 & E. acervulina & KY639280.1 & Sudan \\
12 & E. bruneeti & AF446058.1 & Australia \\
13 & E. brunetti & GQ856314.1 & India \\
\hline 14 & E. brunetti & JX853835.1 & India \\
\hline
\end{tabular}

E. maxima, Eimeria maxima; E. acervulina, Eimeria acervulina; E. mitis, Eimeria mitis; E. brunette, Eimeria brunette; E. tenella, Eimeria tenella; US, United States.

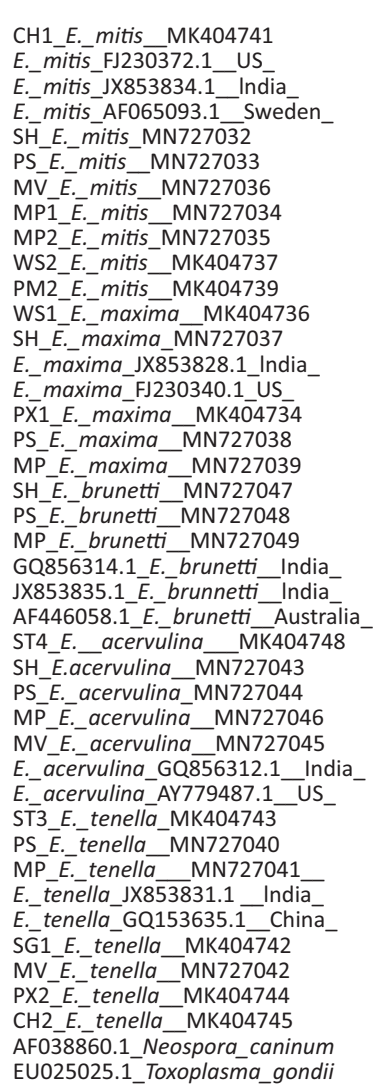
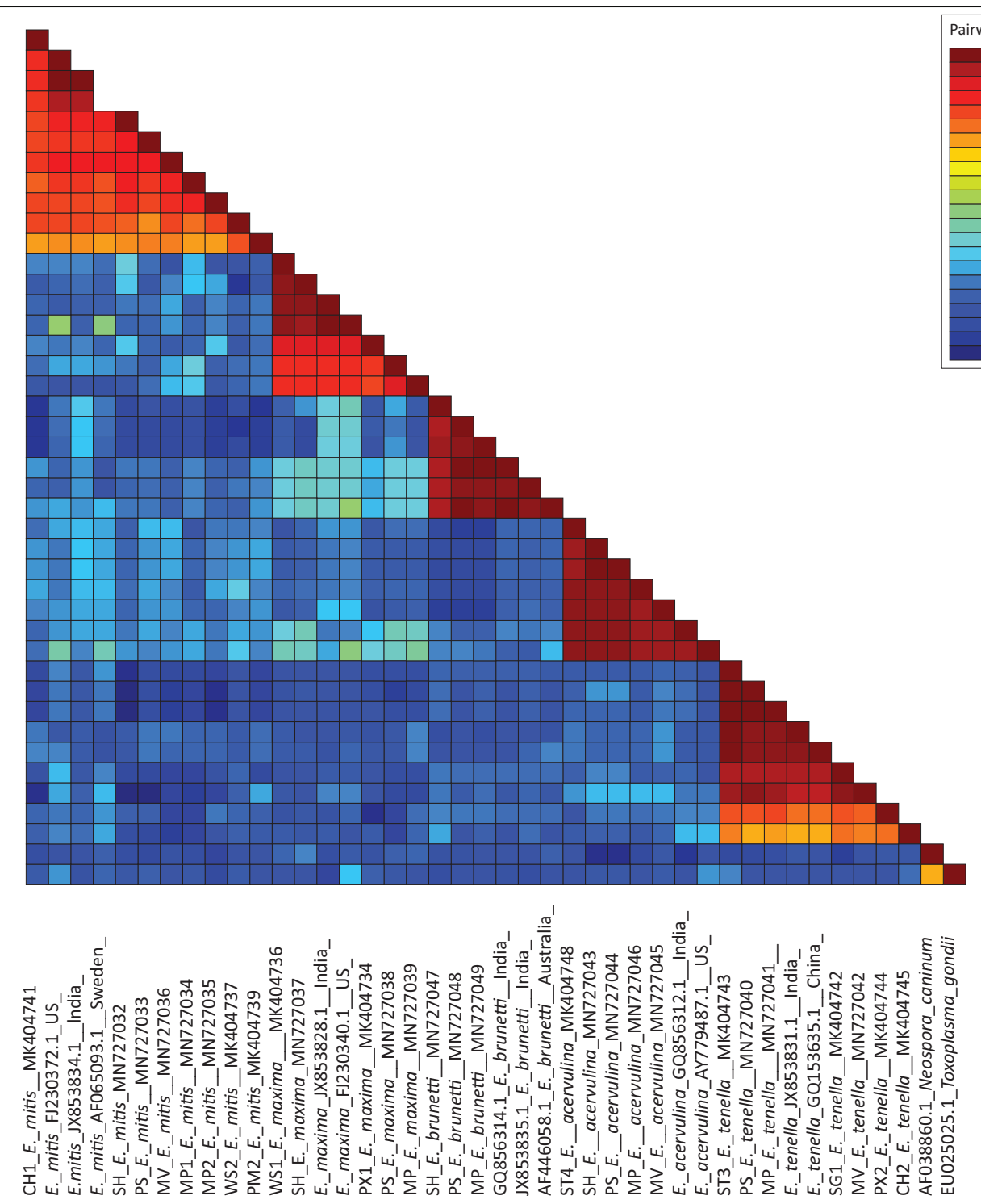

E. maxima, Eimeria maxima; E. acervulina, Eimeria acervulina; E. mitis, Eimeria mitis; E. brunette, Eimeria brunette; E. tenella, Eimeria tenella; US, United States.

FIGURE 1-A1: Pairwise percentage identity of ITS-1 sequences of different Eimeria species. 